\title{
An empirical study to evaluate the architectural design in the construction documents stage using a criteria-based evaluation model
}

\section{Original Article}

\author{
Shukri Elbellahy \\ Department of Architecture, Misr Higher Institute of Engineering and Technology, \\ Mansoura, Egypt
}

\section{Keywords:}

Architectural design phases, criteria-based evaluation, design decision making, working drawings curriculum, working drawings evaluation.

\section{Corresponding Author:}

Shukri Elbellahy, Department of Architecture, Misr Higher Institute of Engineering and Technology, Mansoura, Egypt, Tel: 01112423559, Email: shukrielbellahy@gmail.com

\section{Abstract}

Educational methods of the architecture programs require regular review and continued development to be consistent with the changing standards of the architectural engineering sciences. Although evaluation has an essential role in the education process to make judgments about the quality of the students and their products, few studies have been interested in developing an evaluation method to evaluate the architectural design. Previous studies confirmed the need to develop standards-based evaluation models to evaluate the students' architectural designs in all design stages, as well as an objective weighting method to quantify the weight of each evaluation criterion compared to other evaluation criteria. In this context, this research proposes a criteriabased evaluation model that is oriented to evaluate the students' products of working drawings in the construction documents phase. This research concluded that using a criteria-based evaluation model can achieve a good, accurate, and fair evaluation of the working drawings and can decrease the deviation among multi-evaluators as well as leading to improve the quality of students' working drawings.

\section{INTRODUCTION}

The evaluation has a substantial role in the learning/ teaching process because it allows judging the quality of the students and their products ${ }^{[1]}$. In addition, it is the main component of the instructional design, which looks at how the instructor determines if the learning solution was successful and led to the desired results ${ }^{[2]}$. It is also essential for teaching staff in the educational institutions where they are required to possess the ability to make good, fair, ethical value, on-balance, evidence-based, and defensible judgments ${ }^{[3]}$ about the level of students' achievement according to the educational standards. In addition, they should determine a score that accurately reflects the students' situation in the learning of program curricula $^{[4]}$. Currently, the assessment problem is how to perform an evaluation method ${ }^{[5]}$ that depends on standards. Add to that no available tool to evaluate the comprehensive performance of the building's architectural design except for some tools that consider one or more of the performance criteria of the building's design. Therefore, many educational institutions have made clear initiatives towards criteria-based evaluation methods to make the evaluation process less ambiguous and more transparent ${ }^{[5]}$. In this context, this research presents an empirical study to solve a researchable, significant, and feasible problem of the architectural design evaluation in the construction documents stage.

\section{I Statement of the problem}

A need was emphasized by some previous articles ${ }^{[5,6,7,8]}$ to develop a standards-based evaluation model to evaluate the students' architectural designs as well as an objective weighting method to quantify the weight of each evaluation criterion compared to other evaluation criteria. Also, a previous study ${ }^{[5]}$ concluded that without further scientific contributions, there is no way to develop a standards-based evaluation method to evaluate the architectural design in all design stages. In addition, some students feel aggrieved because the evaluation method of their designs was often non-transparent, holistic, and subjective.

Add to that, the instructor's experience confirmed that the difference between multiple evaluators of the students' architectural designs and working drawings sometimes accounts for more than $50 \%$.

\section{II Research objectives}

This paper proposes a model of criteria-based evaluation that is oriented to evaluate the students' products of architectural designs in the construction documents 
phase as well as aiming to include the senior students in the assessment process to acquire the evaluation skill and improve their performance.

\section{III Research methodology}

The researcher depended on analytic and inductive methods to analyze and induce the collected information sources such as journal articles, conference proceedings, reports, websites, and books related to the research general area. Then, the researcher formulated the research problems, research objectives, and the research conceptual structure. Add to that, the researcher followed empirical and comparative methods to apply the proposed models of criteria-based evaluation as a prototype to solve the research problems. Besides, tools of observation, experiment, and questionnaire were applied to collect information and receive feedback. Finally, a discussion was conducted to interpret the findings, explore the results' significance and draw out conclusions.

\section{Theory \\ II. I Past researches}

Few studies were interested in the role of assessment in architecture education ${ }^{[9]}$. For example, a previous study by Cikis and Cil revealed that most of the design teachers think that criteria-based evaluation is absent in architectural design education $^{[9]}$ as well as highlighting that although the assessment is the driver in the quality of students learning, there is a lack of interest in the role of evaluation in architecture education ${ }^{[9]}$, e.g., a previous study revealed that it is impossible to clarify specific decision-making without indicating the evaluation criteria ${ }^{[5]}$. Also, three studies by Utaberta et al. ${ }^{[5,6,8]}$ revealed that evaluation in the architectural design hall is holistically and subjective. In some cases, some students feel frustrated and believe that they have fulfilled all required work while they are still getting bad grades. While other students subjectively are given good grades and completeness of the task whereas, they are nearly the same ${ }^{[8]}$. Students' frustration because of the absence of transparency in the evaluation process $^{[8]}$. Another study by Yusoff et al. has revealed that performance evaluation depends on human interpretations, which are very subjective and uncertain ${ }^{[10]}$. Uzunoglu proposed a tool for assessing architectural designs, which considers universal architectural design standards of form, function, and construction as the main criteria ${ }^{[7]}$. Those three main criteria include minor criteria. Each one has a relative weighting so that students can identify the quality of their architectural design.Utaberta and Hassanpour ${ }^{[5]}$ presented an evaluation model that includes assignments with some of their criteria based on course objectives, instructor's expectations, and implemented strategies in the design hall. Each task has awarded relative weight ${ }^{[5]}$. However, bad-designed evaluation has the power to hinder learning and deform the progress course ${ }^{[9]}$. While welldesigned evaluation enhances transparency expectations and provides opportunities for students to self-monitor, practice, and receive feedback ${ }^{[9]}$.

A study by Oluwatayo et al. ${ }^{[11]}$ revealed that nominal attention was given to the differences in evaluation criteria at the architectural schools. In addition to their effect on deciding the efficiency rating of the future architects ${ }^{[1]}$. Also, the study confirmed that a statistically significant difference between the scores when the evaluators of different architecture schools or professional institutions use different models of evaluation parameters ${ }^{[11]}$.

The challenge that teachers face is to find ways to motivate students to participate in new teaching strategies that help them achieve their goals and develop successful projects $^{[12]}$. Self-assessment is one of those strategies to enhance the students' evaluation skills and prepare them for professional challenges.Currently, standards-based education considers student self-assessment as a tool to improve student motivation, engagement, and learning ${ }^{[13]}$. Finally, assessment is not an end in itself but a vehicle to improve education ${ }^{[4]}$.

\section{II.II Design process}

The design process is cyclical and iterative and consists of six steps ${ }^{[14]}$ :

1- Problem definition.

2- Information collection.

3- Brainstorm and analyse ideas.

4- Develop solutions/build a model.

5-Ideas presentations for feedback.

6- Design improvement ${ }^{[14]}$.

\section{II.III Basic Design phases}

The main phases of architectural design are:

- Pre-schematic design

- Schematic design

- Design development

- Construction documents

- Bidding

- Construction administration

Figure 1 shows the exerted work by architects in the main design phases ${ }^{[15]}$. 


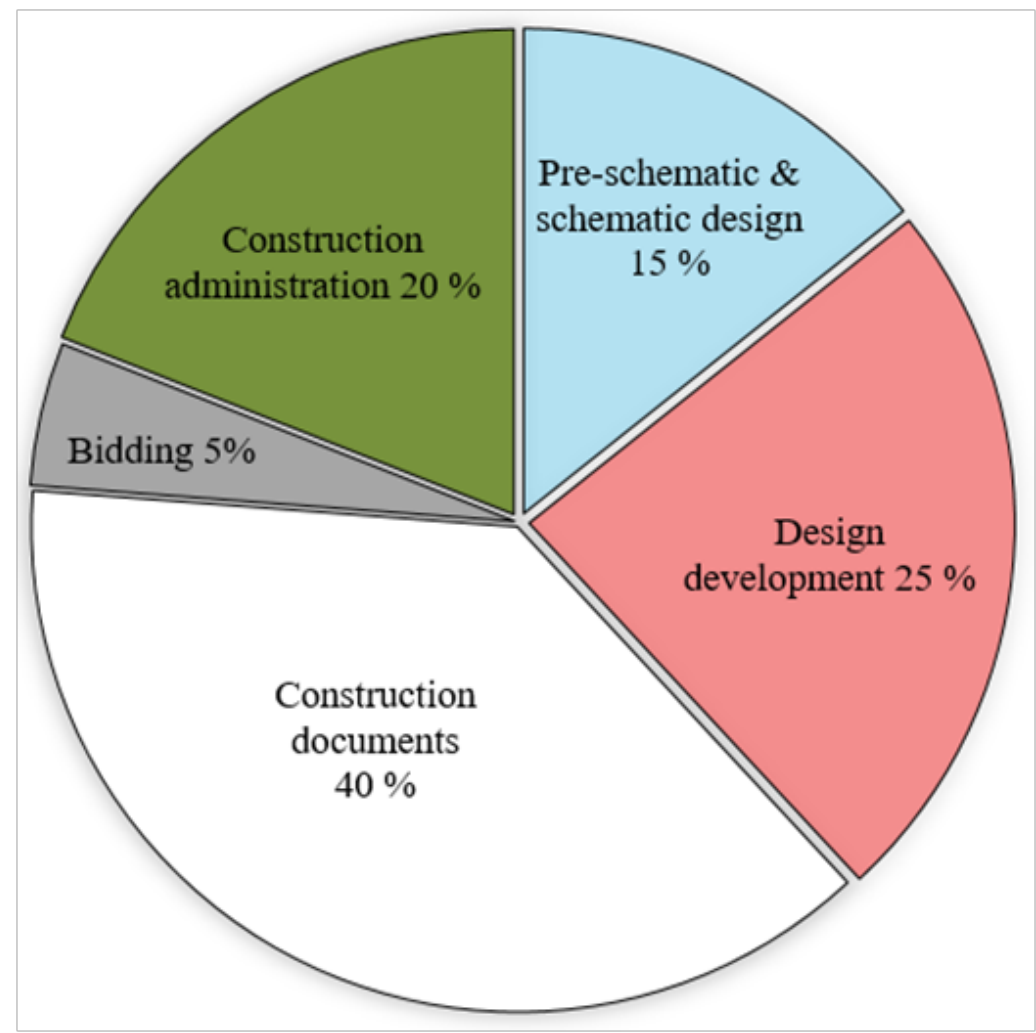

Fig. 1: Proportion distribution of executed work by architects in the design stages ${ }^{[15]}$.

It is clear that the construction documents phase is the biggest stage for the designers and accounts for $40 \%$ of the designers' work ${ }^{[15]}$, which confirmed the working drawings' significance as well as the importance of the evaluation process to produce high-quality working drawings.

In this stage, the designers will finalize all the construction drawings, as illustrated in Figure 2, which include structural details, working drawings, HVAC systems, plumbing installations, electrical installations, gas supplies, and hazards protection systems (fire, earthquake, flood). Designers must ensure that all drawings and specifications consider aesthetics, technical features, and economic considerations.

In addition, construction drawings must be comprehensive, complete, detailed, fully coordinated, constructible, and error-free.

Working drawings of a building design depend on the type, size, and shape of the project and include a site plan, floors' plans, sections, elevations, architectural details, landscape details, roofs, reflected ceilings plans ${ }^{[15,16]}$, windows and doors details, interior design details, fixed equipment details, and movable furniture details as shown in Figure 3.

All drawings must have all technical information and dimensions. Also, architects should prepare wellspecified Specifications to enable bidders to prepare accurate estimates of the quantities, quality, and attributes of the building materials that are essential for issues of construction tender, building permit, and building construction.

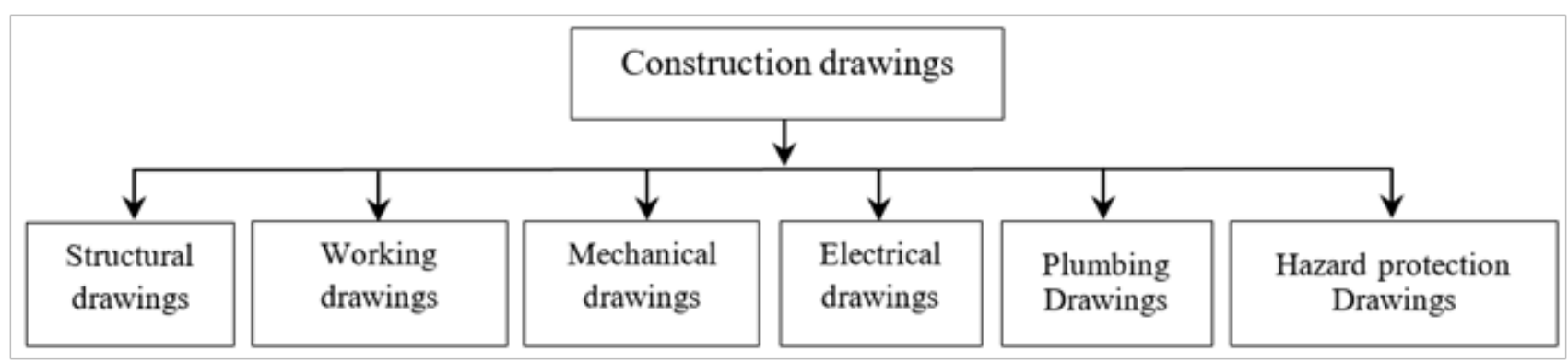

Fig. 2: Classification of construction drawings 


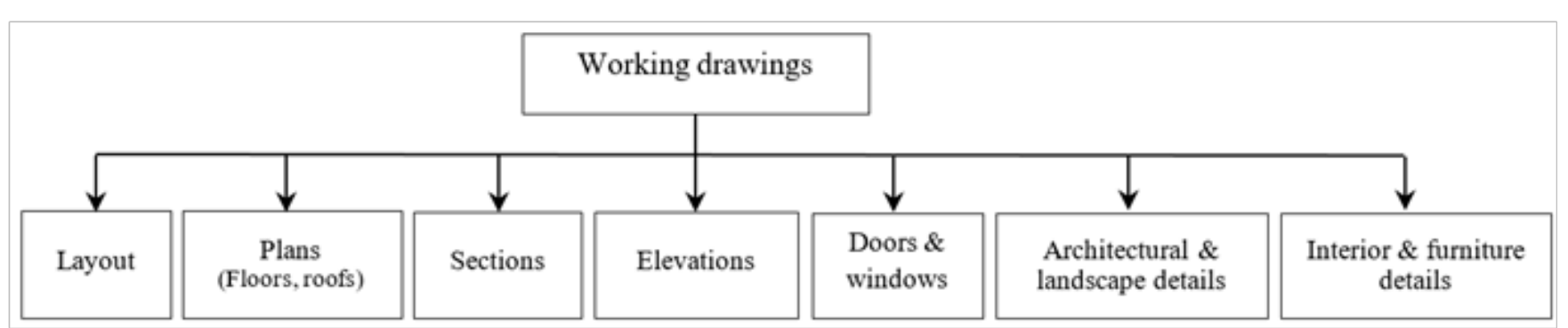

Fig. 3: Classification of building working drawings

II.IV Construction documents phase in the architecture curricula

The main objective of the architecture programs is to graduate architects versed in professional skills and architectural sciences. Therefore, the core of the architecture programs consists of a sequence of architectural design courses ${ }^{[17]}$ which parallel series of theories, history, visual expressions, environmental sciences, structures theories, buildings construction, working drawings, technical installations, simulation \& cad tools, urban design, and elective courses that provide the basis for graduate architects.

Producing comprehensive and applicable architectural designs require great work and time. Therefore the courses of architecture programs are arranged to divide the architectural design phases, as follows, and as shown in Figure 4.

- Architectural design courses concern with the preschematic design, schematic design, and development design phases.

- Courses of buildings construction, working drawings, technical installations, and design of structural systems concern with the construction documents phase.

- Courses of quantities/specifications and Contracts documents concern with the bidding phase

- The course of building construction management concerns with the Administration phase

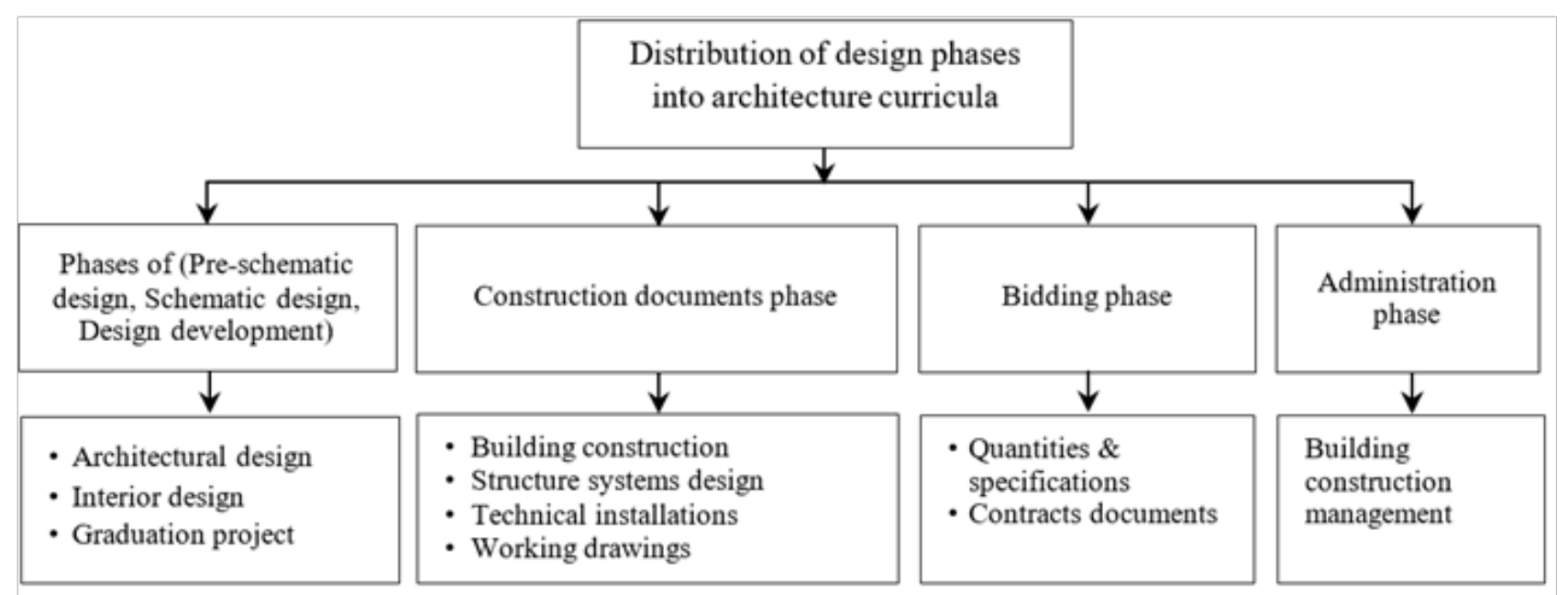

Fig. 4: Distribution of design phases into architecture curricula

\section{II.V Criteria-based evaluation}

Evaluation is the procedure of judging something's quality, importance, or value ${ }^{[3]}$. Also, it is an act of passing judgment based on a set of standards ${ }^{[1]}$. A good evaluation should have four qualities: reliability, standardization, validity, and practicality,while criteria are attributes, rules, conditions, or facts used as standards to evaluate something ${ }^{[3]}$. Recently, using standards in the evaluation process has become more widespread that standards provide openness and transparency in the evaluation and clarify the basis of assessment ${ }^{[18]}$. Also, the criteria support focusing on opportunities and needs for quality improvement ${ }^{[18]}$.

\section{II.V.I Importance of criteria-based evaluation}

- Achieving a transparent, defensible, consistent, reliable, fair, and reproducible evaluation process

- Encouraging consistency and decreasing the deviation among multiple evaluators by sharing the same marking criteria $^{[19]}$.

- Limits the possibility of unfair subjective judgment

- Effective in working drawings' evaluation

\section{II.V.II Students' Self-evaluation}

Self-evaluation is a strategic tool to improve students' performance. However, involving senior students in the 
evaluation process has many advantages such as:-

- Students gain intellectual skills such as: evaluating the characteristics and performance of the building components and systems ${ }^{[20]}$.

- Increase the students' responsibility and objectivity.

- Transform the role and status of the students from passive learners to active learners.

- Improve the students' understanding of the subject matter, skills, and processes.

- Support students to improve the quality of their products (working drawings).

II. VI Current evaluation method of architectural design

Many architecture schools around the world are applying similar evaluation methods to evaluate the students' designs in architectural design courses. These methods depend on the course instructors' scientific background and experience. The evaluation method considers some or all main performance criteria such as aesthetic, functional, structural, social, environmental, economic, and safety ${ }^{[21]}$ as well as sub-criteria that originate from each main criterion according to the level of the architectural design course in the study plan of the architecture program. These selected criteria are a mix of qualitative and quantitative evaluation criteria that are used to evaluate a mix of qualitative and quantitative input data in the architectural design drawings.

Quantitative data are measurable quantities such as lengths, masses, numbers, and percentages while qualitative data are descriptive and regards aesthetic aspects of building design such as space, form, shape, size, texture, balance, unity, color, symmetry, proportion, pattern, decoration, etc. That expresses beauty and taste and can be noticed but cannot be measured. However, instructors should award a relative weighing or a score to each parameter in the evaluation criteria mix of student's achievement. Currently, there is no agreement about using an integrated evaluation model based on specified performance standards and their relative weights to evaluate the buildings' architectural designs. However, this kind of grading model still depends on the course instructor's opinion that may be a subjective judgment in some cases, as well as occurring of a huge deviation among multiple evaluators, are possible.

In the final presentation of the architectural design courses, each student should submit the project analytical studies, concept, layout, floors' plans, sections, facades, perspectives, details, and project models according to the predetermined format, scale, and presentation techniques. The course instructors divide the total grade on the required design assignments' (analytical studies report, architectural design drawings', project model, oral presentation of the project). In this context, the instructor evaluation of the students' works in the current working drawing course is based on the evidence of achievement ${ }^{[22]}$ as classified in Figure 5.

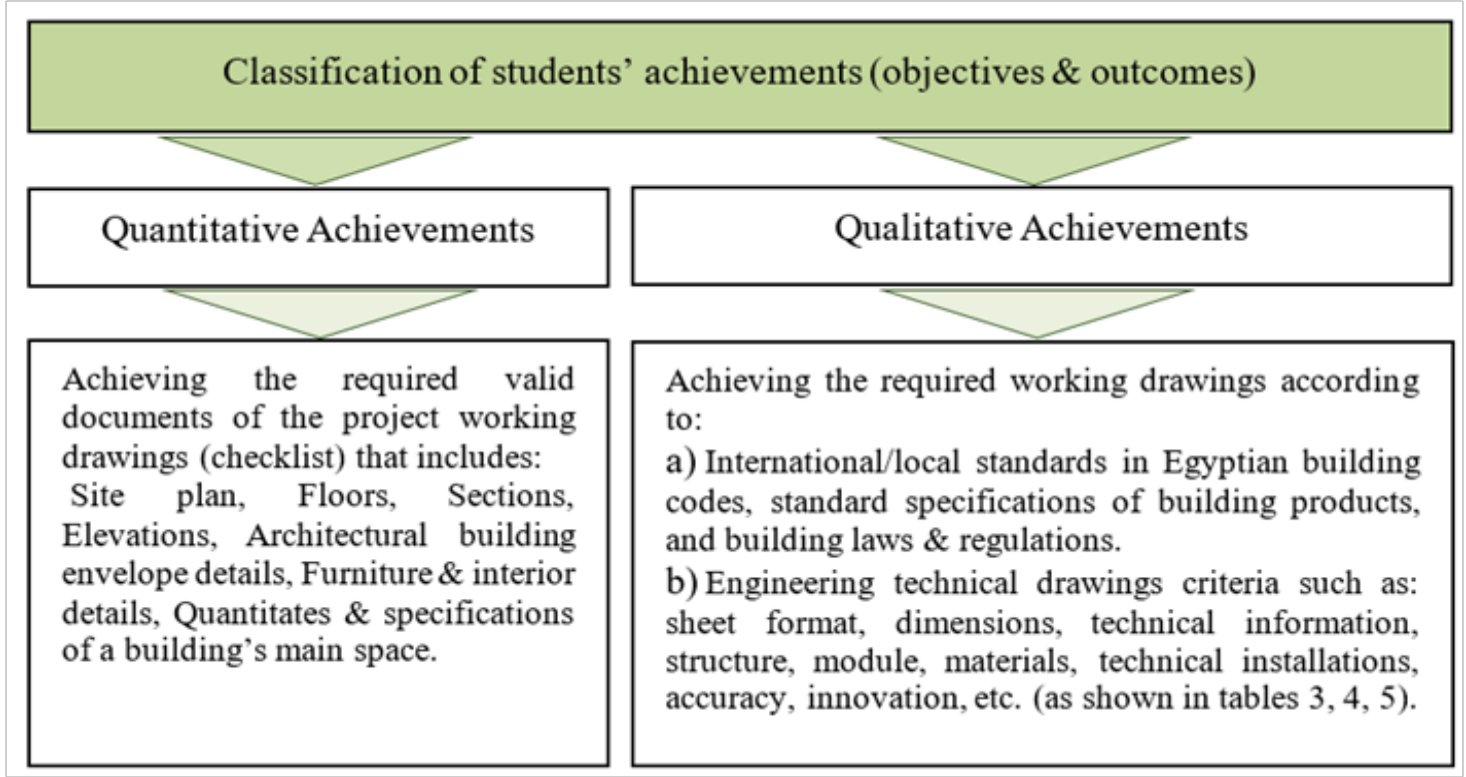

Fig. 5: Classification of students' achievements (objectives and outcomes)

The given grade is equivalent to the achievement level in the submitted design documents' (achievements evidence), as shown in Table. 1. In this context, student's achievement evidence in the working drawings project is a mix of quantitative and qualitative objectives /outcomes that are documented in the project's documents (working drawings sheets, quantities and specifications tables, details models) and are evaluated using a mix of qualitative and quantitative performance indicators of building design against standards in international/local building codes, building laws and regulations.

In addition, the working drawings should meet the predetermined presentation criteria of the project working drawings, as shown in Tables 3, 4, 5 . 
ESMT, Shukri Elbellahy, 2020

Table 1. Levels of the students' achievements in the working drawings of the building design projects.

\begin{tabular}{|l|c|c|c|c|c|c|}
\hline Grade type & \multicolumn{7}{|c|}{ Achievement level } \\
\hline Letter Grade & A & B & C & D & E & F \\
\hline$\%$ Bands & $85: 100$ & $75: 84$ & $65: 74$ & $50: 64$ & $30: 49$ & $0: 29$ \\
\hline Project appreciation & Excellent & Very good & good & Pass & Poor & Very poor \\
\hline Project Status & \multicolumn{7}{|c|}{ Succeed } \\
\hline $\begin{array}{l}\text { Notice: The completion percentage of the Project grade parallels the completion percentage of the project documents that are evaluated } \\
\text { using a mix of quantitative and qualitative performance criteria versus international/local standards. }\end{array}$ \\
\hline
\end{tabular}

\section{An empirical study}

Achieving this empirical study was within the frame of the working drawings curriculum that senior students learn in the department of architecture. The working drawings curriculum is the main course for studying architectural designs in the construction documents phase. The students learn them for four semesters or more, and the course duration time per week is at least six credit hours. The study plan of the architecture program allocated two hours to lecture and allocated the other four hours to tutorial and criticism sessions. Many architecture schools in Egypt and other countries follow a similar traditional method to educate working drawings courses. The teaching method depends on lectures and tutorials.

- Topics of this course as the final course of working drawing courses in the department of architecture focused on developing students' skills in preparing the working drawings of interior design details, installations details, and furniture details for a large-scale project.

- The course coordinator gave the lectures, while the course coordinator and tutors gave the tutorial sessions.

- Lectures began with an introduction to the course objectives, course contents (lectures, assignments), evaluation criteria, grading system, submissions' schedule.

- Students began with selecting a design project from their previous designs in the third year to prepare their working drawings.

- If the selected design project was too large, each student could choose a small building or a small part of the large-scale project to achieve the required working drawings in the pre-determined course time.

- Each student got a submission schedule that includes the number, scale, specifications of the required drawings, and dates of follow-up and final submissions.

- Each student should fulfil his/her project's working drawings, which contain full detailed plans (floors, ceilings), sections, decoration works details, furniture details, and technical installations details.

- Consideration of climatic and environmental aspects was one of the main objectives in the first part of the course content. Add to that it was an essential part of the project design studies in the architectural design course. Therefore, the course coordinator asked the students to consider the climatic and environmental design criteria while preparing their projects' working drawings.

- Students are encouraged in the lectures and tutorials to prepare buildings' envelope details that are consistent with Egypt climate and environment such as green roof, heat insulation, double or triple glazed windows, and selecting Egyptian natural materials.

In other words, they should apply strategies for improving the buildings' energy efficiency, as shown in Figure $6^{[23]}$.

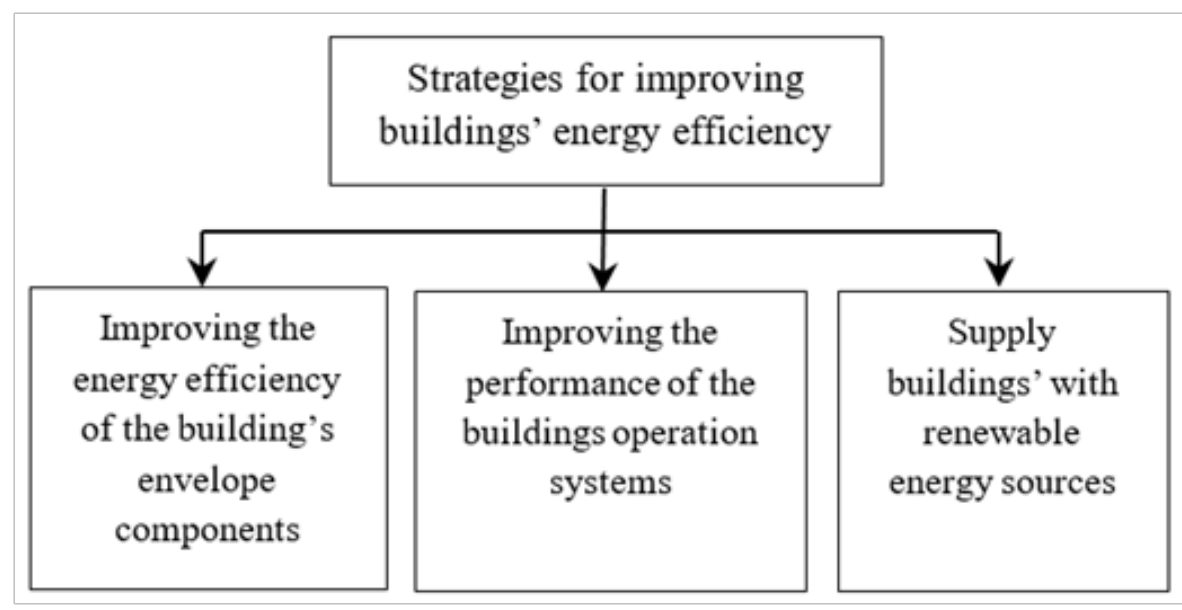

Fig. 6: Strategies for improving buildings' energy efficiency [23]. 
In addition, they should innovate construction details while they prepare the working drawings of their projects (as shown in Figure 7). Every week the instructor gave a lecture on the scheduled topic contains the lecture objectives, similar case studies, architectural and constructional details of the building components, as shown in Figure 7 as well as giving general feedback about the previous and subsequent submissions.

In the tutorial hours, the instructor and the tutors explained to the students (individual and in-groups) how to solve the technical problems of preparing the required working drawings.

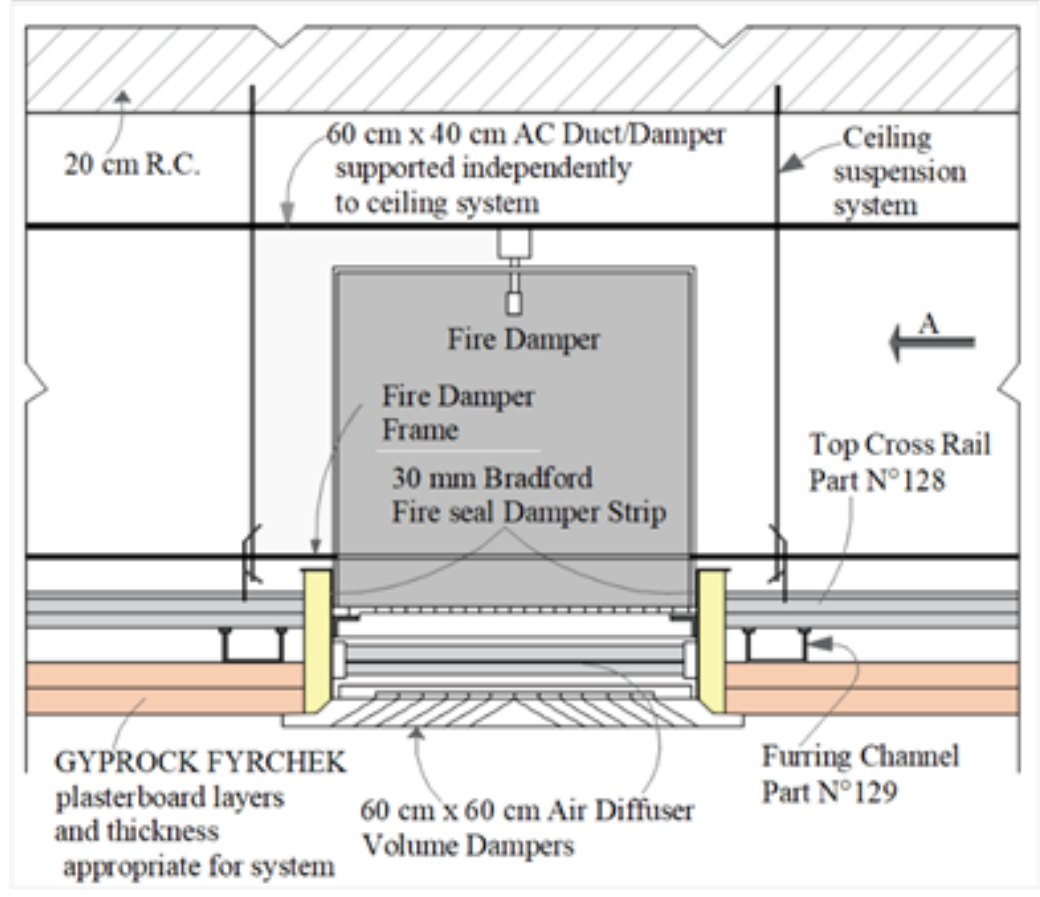

Fig. 7: Detail of Air Conditioning duct/damper penetration in the ceiling (source: www.gyprock.com.au) ${ }^{[24]}$.

Every week at the end of the tutorial hours, the course coordinator and the tutors evaluated the students working drawings and awarded each student's work grade and feedback (feedback includes drawings errors and suggestions to develop the details of the building components).

After evaluating exercise-1 of students' works, the course coordinator and the tutors found that the drawings contained significant technical errors. The instructor awarded scores to the students' works using the proposed models, and the tutors awarded holistic scores to those works. Table 2 shows considerable differences between course coordinator scoring and tutors scoring. However, maybe due to the variation in the practical experience and scientific background of course teamwork members, or due to holistic and subjective judgments.

Table 2: Significant differences between course coordinator scoring and tutors scoring for Exercise-1

\begin{tabular}{l|c|c|c|c|c|c|c|c|c|c|c|c}
\hline Student No. & 1 & 2 & 3 & 4 & 5 & 6 & 7 & 8 & 9 & 10 & 11 & Mean Deviation \\
\hline Deviation (\%) & 52.6 & 22 & 4.4 & 5.6 & 44.8 & 48.7 & 24.8 & 45 & 39.4 & 2.2 & 13.6 & 27.55 \\
\hline
\end{tabular}

Before evaluating exercise-2 of students' works, the course coordinator divided the total grade into the exercise drawings (plans $40 \%$, interior sections $40 \%$, interior details $20 \%$ ), which led to decreasing the deviation in some cases. However, there remains a significant deviation between the instructor's evaluation and the tutors' evaluation in other cases. Also, the working drawings of the students still contain remarkable and repeated errors that can be summarized as follows:

- mistakes in sheet format

- mistakes in structure systems

- mistakes in dimensions and technical information

- mistakes in layers of floors and roofs

- inaccurate drawings 
- mistakes in furniture details

- incompatible details with other building plans

The course coordinator always gave the students detailed feedback about the strengths and weaknesses of their works, with suggestions for improvement as well as helping them to know how to exceed the gap between their actual status and the intended status ${ }^{[25]}$.

The lack of a criteria-based evaluation method led the course coordinator to prepare and apply a criteria-based evaluation model to make the evaluation process more accurate, fair, acceptable, reproducible, and defensible.

The course coordinator clarified the proposed- model for the tutors to overcoming the problem of the enormous deviation between them and the course coordinator related to the evaluation results of the students' works in some cases.

\section{Effectiveness considerations}

Considering the following points before applying the proposed models:

- Building design decision-making considers many of the building performance criteria such as functional, aesthetic, structural, environmental, and social criteria that aim to achieve a high-performance building design. The complexity of the architectural design decisions arises from the fact that each decision depends on a large number of evaluation criteria that might change according to the building design phase. That means each design phase relates to partially different requirements and subsequently different evaluation criteria.

- The following models are a transition from subjective judgment to objective judgment, which limits the possibility of making unfair subjective judgments.

- The instructor considered some criteria that focus on evaluating the working drawings to avoid a cumbersome evaluation process within the predetermined course time when applying more evaluation criteria.

- The course coordinator assigned a relative weight (points) to each evaluation parameter in the proposed model, which depended on the instructor's scientific background and practical experience.

- The following models, as shown in table 3, table 4, and table 5, are used to evaluate the students' working drawings, such as plans, sections, and architectural details. - The course coordinator asked the tutor to consider the models of criteria-based evaluation in evaluating exercise- 3 and exercise- 4 of students' drawings, which led to an additional decreasing in the deviation between the instructor grading and the tutor grading, in some cases of students' drawings, as shown in table 6 .

- The course coordinator asked the senior students to use the proposed models in evaluating their working drawings as an opportunity to detect the weaknesses and strengths as well as finding out the lacks, omissions, and faults of these drawings. Besides, acquire the evaluation skill.

Table 3: Criteria-based evaluation model for building floor plans.

\begin{tabular}{l|c|c|c|c|c|c|c|c|c|c}
\hline Sheet Format & $\begin{array}{c}\text { Module } \\
\text { and } \\
\text { Axis }\end{array}$ & $\begin{array}{c}\text { Structure } \\
\text { system }\end{array}$ & $\begin{array}{c}\text { Openings } \\
\text { (doors, } \\
\text { windows) }\end{array}$ & $\begin{array}{c}\text { Furniture } \\
\text { and } \\
\text { appliances }\end{array}$ & $\begin{array}{c}\text { Decoration } \\
\text { works }\end{array}$ & Dimensions & $\begin{array}{c}\text { Drawing } \\
\text { technical } \\
\text { data }\end{array}$ & $\begin{array}{c}\text { Finishing's } \\
\text { tables }\end{array}$ & $\begin{array}{c}\text { Accuracy } \\
\text { and } \\
\text { innovation }\end{array}$ & $\begin{array}{c}\text { Total } \\
\text { points }\end{array}$ \\
\hline 10 & 5 & 10 & 10 & 20 & 5 & 10 & 5 & 10 & 15 & $100 \%$ \\
\hline
\end{tabular}

Table 4: Criteria-based evaluation model for building vertical sections.

\begin{tabular}{l|c|c|c|c|c|c|c|c|c|c}
\hline Sheet Format & $\begin{array}{c}\text { Module } \\
\text { and } \\
\text { Axis }\end{array}$ & $\begin{array}{c}\text { Structure } \\
\text { system } \\
\text { elements }\end{array}$ & $\begin{array}{c}\text { Layers } \\
\text { of (roof, } \\
\text { ceiling, } \\
\text { floor) }\end{array}$ & $\begin{array}{c}\text { Doors, } \\
\text { windows, } \\
\text { skylights }\end{array}$ & $\begin{array}{c}\text { Furniture, } \\
\text { appliances, } \\
\text { decoration } \\
\text { works }\end{array}$ & Dimensions & $\begin{array}{c}\text { Drawing } \\
\text { text and } \\
\text { technical } \\
\text { information }\end{array}$ & $\begin{array}{c}\text { Finishing's } \\
\text { tables }\end{array}$ & $\begin{array}{c}\text { Accuracy } \\
\text { and } \\
\text { innovation }\end{array}$ & $\begin{array}{c}\text { Total } \\
\text { points }\end{array}$ \\
\hline 10 & 5 & 15 & 10 & 5 & 20 & 10 & 5 & 10 & 10 & $100 \%$ \\
\hline
\end{tabular}

Table 5: Criteria-based evaluation model for building components details.

\begin{tabular}{l|c|c|c|c|c}
\hline Sheet Format & $\begin{array}{c}\text { Shape and content } \\
\text { of details }\end{array}$ & $\begin{array}{c}\text { Dimensions, } \\
\text { technical } \\
\text { information, scale }\end{array}$ & $\begin{array}{c}\text { Arrangement of the } \\
\text { detail components }\end{array}$ & $\begin{array}{c}\text { Accuracy and } \\
\text { innovation }\end{array}$ & 15 \\
\hline 10 & 40 & 30 & 5 & $100 \%$ \\
\hline
\end{tabular}


Table 6: Decreasing the differences between course coordinator evaluation and tutor evaluation for exercise-3.

\begin{tabular}{l|c|c|c|c|c|c|c|c|c|c|c|c}
\hline Student No. & 1 & 2 & 3 & 4 & 5 & 6 & 7 & 8 & 9 & 10 & 11 & Mean Deviation \\
\hline Deviation (\%) & 10 & 5 & 10 & 15 & 20 & 10 & 20 & 5 & 20 & 30 & 5 \\
\hline
\end{tabular}

Students submitted the self-evaluation of their works and the required final working drawings of their projects.

The course coordinator evaluated the final submission of students' works and found that the deviation between his evaluation and the students' self-evaluation was considerable in many cases. However, the effectiveness of students' self-evaluation depends on the attitude, objectivity and serious response of each student. Finally, the improvement of students' final submissions quality comparable to the initial submissions was remarkable, as shown in fig. 9.

To know the students' opinions and attitudes about the effect of using the model of criteria-based evaluation on improving their evaluation skills and the quality of their working drawings, the instructor asked them to fill a questionnaire after the completion of the course. The questionnaire questions concerned with the following:

(a) If the self-evaluation task improves the quality of their working drawings?

(b) If the self-evaluation task helps senior students to acquire the evaluation skill of working drawings?

(c) If they prefer self-evaluation tasks' during the semester or only at the end of the semester?

\section{RESULTS}

Applying the model of criteria-based evaluation in evaluating students' working drawings led to decreasing the mean deviation between instructor evaluation and tutor's evaluation from $27.55 \%$ to $13.63 \%$, as shown in Tables 2 and 6.

Of course, through more practice and training, the mean deviation among assessors will decrease significantly.

Agreement by the majority of participants' students to the positive effect of applying the evaluation models that improve the quality of their working drawings, as shown in Figure 8.

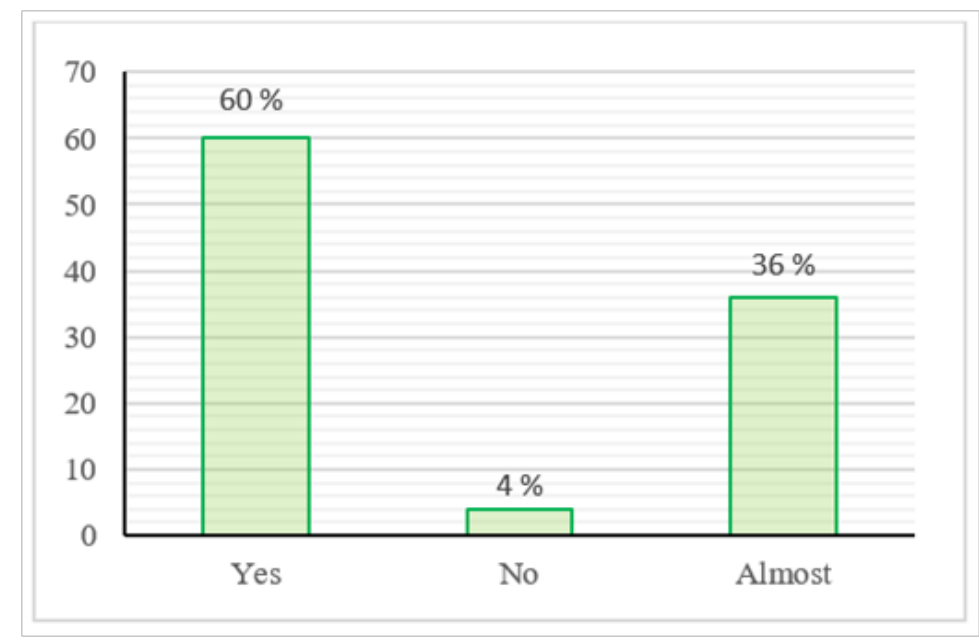

Fig. 8: Students' answers to the question (a) if the self-evaluation task improved the quality of their working drawings

Improving the quality of the final submissions compared to the first submissions of the students working drawings' is explicit in Figure 9. As shown in Figure 10, the majority of participants'students agree that the self-evaluation task helped them to acquire the evaluation skill of working drawings. As shown in Figure 11, voting the majority of participants' students for preferring self-evaluation tasks' during the semester and not just at the end of the semester. 


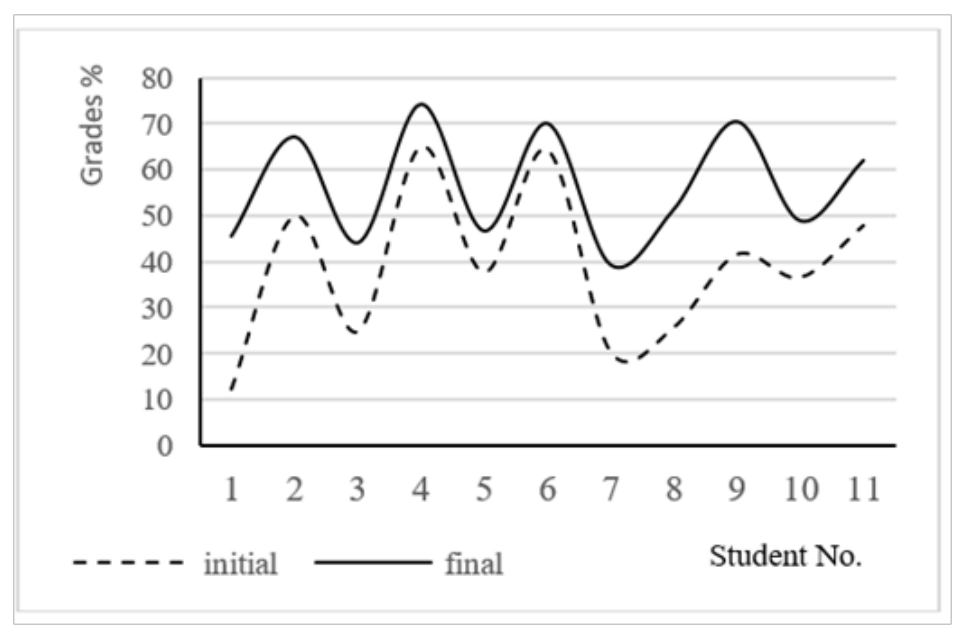

Fig. 9: Improving the final submission quality compared to the initial submission of students' working drawings

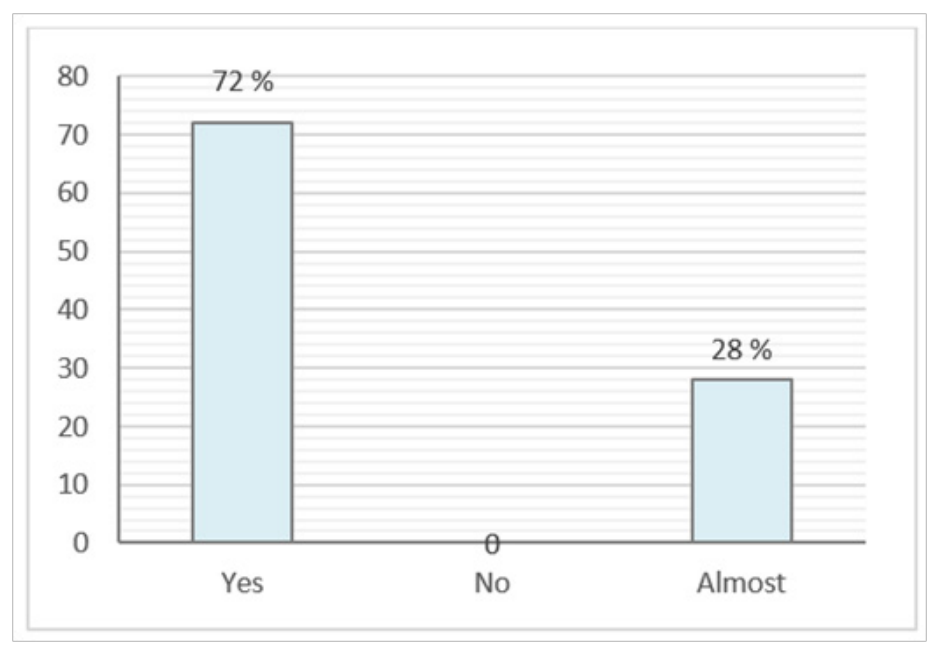

Fig. 10: Answers of participants students' to question (b) if the self-evaluation task helped them to acquire the evaluation skill of working drawings.

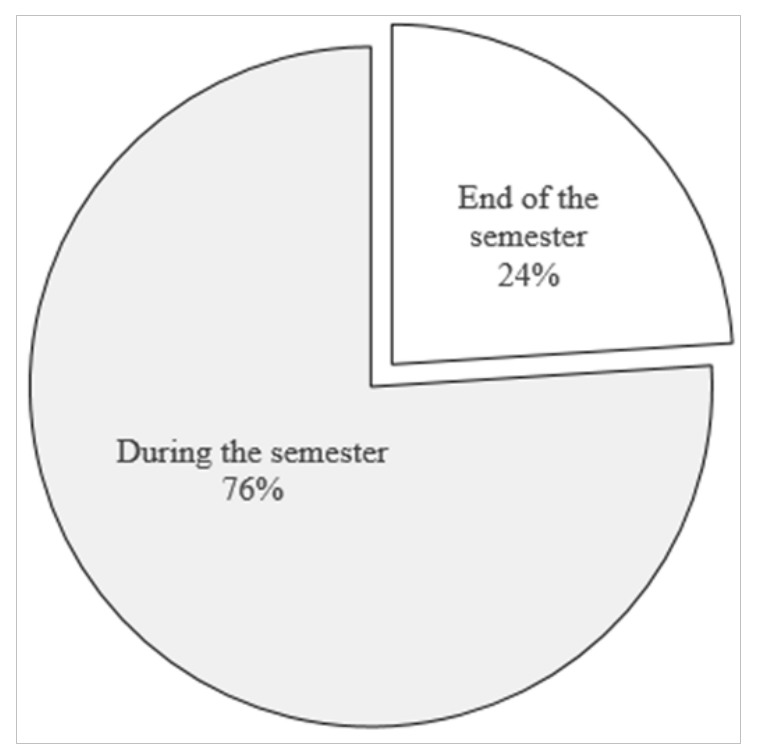

Fig. 11: Answers of participants students' to question (c) if they prefer self-evaluation tasks' during the semester or only at the end of the semester. 


\section{DISCUSSION}

Changing the evaluation process from subjective decisions influenced by subjective instants, and their results may not be reproducible, to objective judgments based on facts rather than intuition was a requirement to previous researches ${ }^{[5,6,8,9,10,26]}$. This research achieved its objectives by sharing in filling the knowledge gap in architectural design evaluation. An objective method of criteria basedevaluation was proposed to evaluate the students' working drawings, which reduced the deviation between the multievaluators, as well as leading to a positive effect on the quality of the students' working drawings.

The strengths of this research include providing an evaluation model that is applicable, reproducible editable, and defensible. Besides, making errors in assigning scores by this model is very limited, and it is easy to detect and correct.

The proposed model's weakness may be that it consumes slightly more time than the current holistic grading model of working drawings. However, man can argue that good, accurate, and fair evaluation of students' works deserve the exerted time.

In this empirical study, the researcher applied the selfevaluation just to the final submission of the project. However, the students voted that they prefer self-evaluation during the semester to acquire enough training and better experience in the evaluation of working drawings. i.e., applying the self-evaluation task during the course period makes it a tool for learning, and not only evaluating learning outcomes, which improves the performance of the students and their products of working drawings as well as increasing the responsibility and objectivity of the students. In addition, the self-evaluation task transforms the students' status from passive learners to active learners.

The proposed criteria-based evaluation model can practically set the evaluation on the top of the hierarchy of learning ${ }^{[27]}$ and limits considerably unfair subjective judgments.

This research supported previous suggestion ${ }^{[1]}$ that confirms the relevance of having standardized grading parameters as a basis for a unified system of assessment to achieve the equity of measures, grading, and marking for all architectural schools.

Finally, this research provides an educational evaluation tool that considers a significant contribution to the development of educational evaluation methods for building design in the construction documents phase. The proposed models support evaluators to make accurate and fair judgments as well as encouraging consistency and decreasing the deviation between multiple evaluators.

\section{CONCLUSION}

Using the proposed criteria-based evaluation model decreased the deviation between the evaluators and improved the quality of the students' designs.

Applying the proposed criteria-based evaluation model achieved a good, accurate, and fair evaluation of students' working drawings, and if an error occurred, it is easy to detect and correct.

Applying self-evaluation during the course period will improve the performance of the students and their products as well as increasing their responsibility and objectivity.

\section{REFERENCES}

[1] Key difference, website, https://keydifferences.com, (accessed 4 July 2020).

[2] Association for Talent Development (ATD), website, https:// www.td.org/talent-development-glossary-terms/what-is-instructionaldesign,(accessed 29 August 2020).

[3] Cambridge University Press, website, https://dictionary.cambridge. org, (accessed 12 June 2020).

[4] Victoria state government, Department of Education and Training, website, www.education.vic.gov.au/Documents/school/teachers/, (accessed 29 August 2020).

[5] Utaberta, N.,Hassan pour, B., Reconstructing a Framework for Criteria-Based Assessment and Grading in Architecture Design Studio,UKM Teaching and Learning Congress 2011,Procedia - Social and Behavioral Sciences,2012,Volume 60, pp. 142 - 149. https://doi. org/10.1016/j.sbspro.2012.09.360.

[6] Utaberta, N., Hassanpour, B., Bahar, M. A., An Evaluation of CriteriaBased Assessment and Grading in Architecture Design, Research Journal of Applied Sciences, Engineering and Technology, 2013, Volume 5, Issue 2, pp. 346-352, http://dx.doi.org/10.19026/rjaset.5.4956.

[7] Uzunoglu, K., Uzunoglu, S., Project evaluation process with classified objective criteria in architectural education, Procedia - Social and Behavioral Sciences, 2001,Volume 28, pp. 1004 - 1010, https://doi. org/10.1016/j.sbspro.2011.11.185.

[8] Utaberta, N., Hassanpour, B., Bahar, M. A., CheAnib, A. I., A Comprehensive Learning of Architecture Education: Understanding Critique Session as Learning Process and Criteria-Based Assessment in the Architecture Design Studio,6th International Forum on Engineering Education (IFEE 2012), Procedia - Social and Behavioral Sciences, 2013, Volume 102, pp. 21 -32,https://doi.org/10.1016/j.sbspro.2013.10.709.

[9] Cikis, S, and Cil, E., Problematization of assessment in the architectural design education: First year as a case study, World Conference on Educational Sciences, Procedia Social and Behavioral Sciences,2009,Volume 1, Issue 1, pp. 2103-2110.

https://doi.org/10.1016/j.sbspro.2009.01.369.

[10] Yusoff, Y. M., Omar, M. Z., Zaharim, A., Evaluation of Graduates' Performance using Fuzzy Approach, 6th International Forum on Engineering Education (IFEE 2012), Procedia - Social and Behavioral Sciences, 2013, Volume 102,pp. 64 - 73, https://doi.org/10.1016/j. sbspro.2013.10.714.

[11] Oluwatayo A., Alagbe O., Aderonmu P., Alalade G., Difference in grading parameters in architectural schools and its impact on the competency rating of future professionals, Frontiers ofArchitecturalResearch(2015) 4 230-236, http://dx.doi.org/10.1016/j.foar.2015.06.001.

[12] AboWardah, E. S., Bridging the gap between research and schematic design phases in teaching architectural graduation projects, Frontiers of Architectural Research, 2020, Volume 9, Issue 1, March 2020, pp.82-105, https://doi.org/10.1016/j.foar.2019.04.005.

[13] McMillan, J. H., Hearn, J., Student Self-Assessment: The Key to Stronger Student Motivation and Higher Achievement, Phi Delta Kappa International(www.jstor.org),2008,Vol. 87, No. 1, Democratic Classrooms: A Dialogue (Fall 2008), pp. 40-49.

[14] Chicago architecture center, what is design process? Website, www. discoverdesign.org, Chicago, accessed 29-8- 2020

[15] Rogers E., "Phases of Architectural Design," Wagstaff + Rogers Architects, website, www.wagstaffrogersarch.com $/$ blog/phasesarchitectural-design, (accessed 29 August 2020)

[16] Redlein, A., Modern Facility, and Workplace Management-Processes, Implementation and Digitalization, Springer Nature Switzerland AG, 2020, https://doi.org/10.1007/978-3-030-35314-8

[17] Cornell University, College of Architecture, Art, and Planning, "Architecture program philosophy," website,https://aap.cornell.edu/ academics/architecture/about/studio-culture-policy, NYC, (accessed 29 August 2020)

[18] The Danish evaluation institute, (EVA), Criteria based evaluations, website, www. eva.dk, Copenhagen, 2004. 
[19] University of New South Wales (UNSW), teaching at UNSW, Sydney, website, https://teaching.unsw.edu.au/standards-basedassessment, (accessed 29 August 2020)

[20] National Authority for Quality Assurance and Accreditation of Education, National academic reference standards for engineering (NARS),2nd Edition, 2009

[21]Elbellahy, S., Environmental efficiency of buildings architectural design, Dar Alketab Alhadith, Cairo, 2018

[22]Richard J. Stiggins, Grade level ofachievement reporting:Teacher and Administrator Handbook The assessments that drive academic learning and self-concept are those used by teachers in classrooms, Alberta Education, Alberta, Canada, 2008.

[23] Elbellahy, S., Performance strategies for reducing energy consumption of buildings and related greenhouse gas emissions: A review, Third international conference of Architecture and Urban Planning (AR-
UP 2019), Ain Shams University, Cairo, Egypt, 2019.

[24]Gyprock Ceiling Systems installation guide, website, www.gyprock com.au, (accessed 04 October 2019).

[25] Sadler, R., beyond feedback: developing student capability in complex appraisal, Assessment \& Evaluation in Higher Education, 2010,Vol. 35, Issue 5, pp. 535-550.,https://doi.org/10.1080/02602930903541015

[26] Ghonima, M., Eweda, N., Best practices in managing, supervising, and assessing architectural graduation projects: A quantitative study, Frontiers of Architectural Research, 2018, Volume 7, Issue 3, pp. 424-439,https://doi.org/10.1016/j.foar.2018.06.002.

[27] Benjamin S. Bloom, Max D. Engelhart, Edward Furst, Walter H. Hill, and David R. Krathwohl., Taxonomy of Educational Objectives, Handbook 1: Cognitive Domain, David McKay Company, Inc., New York, https://psych.unl.edu/psycrs/974/Bloom3. pdf,1956. 